\title{
PRESSUPOSTOS EPISTEMOLÓGICOS QUE BALIZAM A SITUAÇÃO DE ESTUDO: ALGUMAS IMPLICAÇÕES AO PROCESSO DE ENSINO E À FORMAÇÃO DOCENTE
}

\section{Epistemological assumptions that underlie Situation Study: some implications for teaching and teacher training}

\author{
Fábio André Sangiogo ${ }^{1}$. Karine Raquiel Halmenschlager ${ }^{2}$. \\ Sandra Hunsche ${ }^{3}$. Otavio Aloisio Maldaner ${ }^{4}$
}

\begin{abstract}
Resumo: Frente às propostas de ensino baseadas em temas que sinalizam reconfiguração curricular, objetiva-se identificar e apresentar pressupostos epistemológicos presentes na Situação de Estudo (SE), bem como destacar implicações destes no ensino e na formação docente. A pesquisa é de natureza qualitativa, desenvolvida mediante a análise de textos publicados que referenciam a SE, e de uma entrevista semiestruturada realizada com um professor idealizador da proposta. A análise dos materiais permite inferir que o principal referencial epistemológico da SE é o bachelardiano, e, no âmbito educacional, o vigotskiano. Contudo, assumir esses referenciais implica construir programas escolares que considerem aspectos do cotidiano do estudante para que, nas interações assimetricamente estabelecidas sobre o objeto em estudo, possa apropriar-se do conhecimento historicamente produzido. Para isso, sinalizase a necessidade de discussões de cunho epistemológico na formação docente, para além dos educacionais, para que se desenvolva um ensino mais coerente com as Ciências e significativo aos estudantes.
\end{abstract}

Palavras-chave: Situação de estudo. Epistemologia. Ensino de Ciências. Formação de professores.

\begin{abstract}
This paper aims to identify and bring forward epistemological assumptions from Study Situation (SE), and detect implications of this for teaching and teacher training. This is qualitative research, developed by analysis of publications that refer to SE and a semi structured interview and was conducted with a teacher mentor of the proposal. The analysis of the materials allows us to infer that the main epistemological reference of SE is Bachelardian and, in the educational sphere,Vigotskian. Taking these references shows how to build school programs, considering aspects from the student's everyday knowledge, so that they can take ownership of the knowledge historically produced in the interactions asymmetrically established for the object under study. So, it signals the need for epistemological discussions in teacher training, in addition to the educational, in order to develop a teaching that is more coherent with the Science and meaningful to the students.
\end{abstract}

Key words: Study situation. Epistemology. Science teaching. Teacher training.

1-3 Programa de Pós-Graduação em Educação Científica e Tecnológica (PPGECT), Centro de Ciências Físicas e Matemáticas, Universidade Federal de Santa Catarina (UFSC). Campus Trindade, Florianópolis, SC, Brasil. 88.040-900.fabiosangiogo@gmail.com

${ }^{4}$ Programa de Pós-Graduação em Educação nas Ciências, Universidade Regional do Noroeste do Estado do Rio Grande do Sul (Unijui). Ijuí, RS, Brasil. 


\section{Introdução}

Muitas são as discussões no cenário educacional, em especial nos últimos anos, acerca do currículo escolar e das possibilidades de sua reconstrução. Com o intuito de investigar e discutir essas possibilidades, diversas pesquisas foram e estão sendo desenvolvidas no contexto do Ensino de Ciências (GALIAZZI et al., 2004; MALDANER; ZANON, 2004). Compreende-se que a reconstrução curricular pode contribuir para a superação da simples transmissão dos conteúdos presentes nos livros didáticos aos estudantes e para uma maior significação dos conteúdos ensinados na escola.

Com base nos Parâmetros Curriculares Nacionais (PCN), entende-se, ao discutir a necessidade de (re)construção dos programas escolares que consideram relações interdisciplinares e contextuais, que o trabalho pedagógico a partir de 'temas' favorece a articulação entre as disciplinas, sejam elas de uma mesma área do conhecimento ou não, desde que se considere o objeto de estudo real, localizado em determinado contexto (BRASIL, 2002).

Contemplando as proposições dos documentos oficiais, uma diversidade de temas é discutida no ensino de Ciências, dentre os quais: temas geradores (DELIZOICOV, 2008), temas polêmicos (FORGIARINI; AULER, 2009), temas transversais (BRASIL, 1998), além de temas que abordam relações entre Ciência-Tecnologia-Sociedade - CTS (CRUZ; ZYLBERSZTAJN, 2001; SANTOS; MORTIMER, 2000). Para a abordagem desses temas, há, na Educação Básica, diferentes enfoques, como estudos que defendem a abordagem de temas como processo de reconfiguração curricular, ou seja, a organização do programa escolar a partir de temáticas, a exemplo da Situação de Estudo (SE) (MALDANER, 2007a; MALDANER; ZANON, 2004;), da abordagem temática freiriana (DELIZOICOV, 2008), dos currículos com ênfase CTS (PINHEIRO; SILVEIRA; BAZZO, 2007; SANTOS; MORTIMER, 2000) e da articulação entre abordagem temática freiriana e o enfoque CTS (AULER; DALMOLIN; FENALTI, 2009; MUENCHEN; AULER, 2007). Essas propostas de reconfiguração curricular possuem diferentes características e referenciais teóricos, mas, de modo geral, apresentam uma proposição comum: superar as limitações do ensino tradicional.

Neste texto será enfocada a proposta de ensino que remete para o processo de reconfiguração curricular denominado SE, em estudo pelo Grupo Interdepartamental de Pesquisa sobre Educação em Ciências (Gipec) da Universidade Regional do Noroeste do Estado do Rio Grande do Sul (Unijuî). Essa proposta tem como referencial teórico a abordagem históricocultural, em especial, as ideias de Vigotski.

Cientes de que os pressupostos educacionais são amplamente discutidos, pelo grupo de pesquisa, em textos que visam orientar o planejamento e desenvolvimento de SE, tem-se como objetivo, neste artigo, a identificação e apresentação de pressupostos epistemológicos presentes na SE, bem como a análise das implicações dos mesmos na proposta de ensino e na formação docente. Desta forma, pretendeu-se responder às seguintes questões: Quais os pressupostos epistemológicos que balizam a proposta de ensino denominada de SE? Quais as implicações desses pressupostos ao se pensar a elaboração e o desenvolvimento de SE em sala de aula? Como esses pressupostos são trabalhados na formação inicial e continuada de professores? 


\section{Procedimentos metodológicos}

O presente estudo é de natureza qualitativa (LÜDKE; ANDRÉ, 1986) e foi realizado a partir da análise de materiais publicados referentes a SE e da realização de uma entrevista semiestruturada com um dos integrantes do Gipec-Unijuí.

Materiais referentes a SE, publicados no âmbito do Gipec, foram localizados nos: anais do Encontro Nacional de Pesquisa em Ensino de Ciências (ENPEC) no período de 2000 a 2009; capítulos de livros; artigos publicados em periódicos que divulgam pesquisas referentes ao ensino e educação em ciências; material publicado em um CD-ROM, decorrente de um 'Programa de Melhoria e Expansão do Ensino Médio' e que configurou um espaço de formação continuada (FRISON, 2006).

Foi analisado, também, o texto base de uma SE, denominada 'Ar Atmosférico', planejada para ser desenvolvida no primeiro ano do Ensino Médio, e que inclui um texto de orientação para professores de Biologia, Física e Química, publicado em CD-ROM (FRISON, 2006). Além de orientar os professores, este texto-base apresenta referenciais teóricos da proposta, servindo como exemplo para a produção de novas SE e sugerindo atividades a serem desenvolvidas em sala de aula.

Após a identificação dos trabalhos, que totalizaram 32 textos/artigos, realizou-se a leitura sistemática dos mesmos, buscando aspectos que pudessem indicar os pressupostos epistemológicos que balizam a SE, bem como implicações destes no processo de organização curricular, na formação de professores e no desenvolvimento de temas em sala de aula, ao ter como referência os materiais analisados.

Cabe salientar que a análise preliminar de estudos desenvolvidos e publicados por integrantes do Gipec-Unijuí sinalizou que as concepções epistemológicas que balizam a SE estão parcialmente explicitadas em diversos de seus textos, o que justifica um estudo aprofundado das mesmas. Reitera-se que, para uma melhor compreensão dessa proposta de ensino, faz-se necessário explicitar, para além dos pressupostos educacionais que são amplamente discutidos nos trabalhos publicados, os pressupostos epistemológicos defendidos pelo referido grupo.

Com base na análise das publicações mencionadas, realizou-se uma entrevista semiestruturada com um dos professores pesquisadores do Gipec-Unijuí, que será codificado como PE (professor entrevistado), escolhido por ser um dos principais propositores da SE, visto que está na autoria da maior parte dos textos analisados neste trabalho, seja quanto (i) à proposição teórica, (ii) à análise de processos de ensino e aprendizagem ou (iii) a reflexões sobre espaços de formação de professores de Ciências que envolvem SE. Tais discussões, por parte do pesquisador, denotam a preocupação com a melhoria da proposição teórica e prática que integra os processos de ensino e formação para o ensino de Ciências envolvendo SE; e, portanto, supõese que interlocuções da reflexão sobre a prática são incorporadas na sua fala, a exemplo de compreensões sobre os limites e as potencialidades da proposta, seja por parte do professor que a implementa ou por parte dos estudantes da Educação Básica e da formação inicial.

A entrevista realizou-se com base em duas questões amplas, organizadas a partir de aspectos levantados por meio da análise dos estudos selecionados: (1) Quais aspectos extraídos dos textos correspondem à visão epistemológica defendida na SE, sobretudo sobre a concepção de Ciência e de produção do conhecimento científico? (2) Quais aspectos destacados dos textos sinalizam possíveis implicações que a perspectiva epistemológica adotada de- 
nota junto ao processo de elaboração e implementação de SE na sala de aula, de modo a possibilitar visões de Ciência e de produção de conhecimento científico mais adequadas às defendidas pelo grupo de pesquisa? Ou seja, buscou-se entender em que medida a perspectiva epistemológica vem se refletindo na perspectiva educacional, em aspectos como: currículo, elaboração de materiais didáticos, formação docente, escolas, ensino, sala de aula.

Nesse viés metodológico, a leitura sistemática dos textos selecionados possibilitou o planejamento da entrevista, a qual permitiu, por sua vez, aprofundar a análise dos textos/ publicações selecionados. Essa articulação entre as diferentes fontes de dados possibilitou uma visão mais ampla sobre a SE, especialmente quanto aos seus fundamentos epistemológicos e ao que é proposto a ser desenvolvido no âmbito da Educação Básica e no âmbito da formação inicial e continuada de professores.

Com o propósito de responder às questões de pesquisa, o texto foi organizado em três tópicos: o primeiro visa contextualizar o leitor sobre alguns aspectos gerais que caracterizam a SE; o segundo apresenta os pressupostos epistemológicos da SE; e o terceiro apresenta consonâncias entre pressupostos epistemológicos e educacionais: implicações na organizaçãa do currículo, no desenvolvimento das temáticas/ensino e na formação de professores.

\section{Alguns aspectos gerais sobre a $\mathrm{SE}$}

A SE começou a ser pensada no âmbito do Gipec-Unijuí no ano de 2000, sendo considerada uma proposta

[...] conceitualmente rica, identificada nos contextos de vivência cotidiana dos alunos fora da escola, sobre a qual eles têm o que dizer e em cujo contexto, eles sejam capazes de produzir novos saberes, expressando-lhes significados e defendendo seus pontos de vista. (MALDANER; ZANON, 2004, p. 57)

Desta forma, em consonância com a teoria sócio-histórico-cultural, ao se elaborar uma $\mathrm{SE}^{5}$, são considerados elementos da vivência dos alunos, para além da necessidade de mediação de conceitos científicos. Isso no entendimento de que essas vivências e as relações que o aluno estabelece com seu meio são importantes na construção do conhecimento que possibilita a formação das funções psicológicas superiores, como a capacidade de generalizar e de abstrair (VIGOTSKI, 2001). Ao se abordarem, em sala de aula, situações já conhecidas dos alunos, há a possibilidade de os mesmos interagirem intensamente com o objeto de estudo e com o professor, o que favorece o aprendizado (MALDANER et al., 2001).

Maldaner (2007a) explica que a SE pode configurar um projeto de estudo, com duração de um trimestre ou bimestre, e que possa conter, além desta, outras características:

\footnotetext{
${ }^{5}$ Entre as SE planejadas e implementadas em escolas de Educação Básica, estão: ‘Geração e gerenciamento dos resíduos sólidos provenientes das atividades humanas" (UNIVERSIDADE REGIONAL DO NOROESTE DO ESTADO DO RIO GRANDE DO SUL, 2002), 'Ser humano e ambiente: percepção e interação' (AUTH; MELLER, 2005), 'Alimentos, produção e consumo: alimentação humana' (BOFF; HAMES; FRISON, 2006) e 'Ar Atmosférico: uma porção do mundo material sobre a qual se deve pensar' (MALDANER, 2007b).
} 
[...] contemplar um número relativamente pequeno de conceitos centrais sendo estes sempre representativos da disciplina, compondo uma totalidade para cada disciplina e para o conjunto delas; [...] transacionar apenas significados iniciais para conceitos que aparecem pela primeira vez, podendo evoluir no desenvolvimento das SEs; estimular a produção criativa e coletiva dos estudantes sobre o entendimento da situação estudada como uma totalidade; [...] permitir que sejam significados os conhecimentos científicos contemporâneos, uma decorrência natural quando se estuda uma situação concreta e as soluções tecnológicas atuais. (MALDANER, 2007a, p. 249-250)

Neste sentido, percebe-se que, em cada SE, contempla-se uma situação vivencial que é assumida por professores e estudantes, de modo que se torna necessário romper a estrutura curricular disciplinar do Ensino Médio, no que tange à ruptura entre as disciplinas de uma mesma área bem como à sequência de conteúdos tradicionalmente trabalhados em cada disciplina (MALDANER, 2007a).

Na prática, após a escolha da situação/tema a ser estudada, uma equipe de professores organiza-se para explicitar entendimentos considerados essenciais em torno dos conceitos que serão utilizados em cada disciplina e que serão intencionalmente explicitados aos alunos (MALDANER, 2007b) com o objetivo de contribuir no estudo da situação vivencial. Alguns conceitos são estudados em diferentes disciplinas, e tendem a ser retomados em diversos momentos da SE e em SE distintas, a exemplo do trabalho desenvolvido em uma das escolas (acompanhada pelo Gipec) em que as SE são organizadas de forma a compor o programa escolar de Física, Química e Biologia do primeiro e segundo ano do Ensino Médio (HALMENSCHLAGER, 2010). Pretende-se, com essa organização, o desenvolvimento de um trabalho interdisciplinar que não considera a justaposição e diluição das disciplinas.

Para o desenvolvimento dos temas em sala de aula, são propostas três etapas (AUTH, 2002; GEHLEN; MALDANER; DELIZOICOV, 2012): 1) Problematização, definida como espaço para os alunos expressarem o seu entendimento sobre o tema a ser abordado; 2) Primeira elaboração, momento em que são estudados textos de aprofundamento da temática apresentada na Problematização e são realizadas atividades que permitem a socialização da situação em estudo; 3) Função da elaboração e compreensão conceitual, etapa em que o aluno começa a relacionar as palavras representativas dos conceitos científicos com o contexto no qual as mesmas são empregadas.

Durante as aulas, utilizam-se: diversas fontes de informação e textos provenientes de livros didáticos, internet, revistas, jornais, documentários, filmes e outros. Uma variedade de alternativas metodológicas pode ser inserida, de forma a promover o estudo da SE (experimentação, trabalho em grupo, mapas conceituais, pesquisas etc.), além da possibilidade de se fazer alguma visita de campo ou convidar outros profissionais para realizarem palestras sobre aspectos da SE.

Nas SE, a abordagem de situações conhecidas pelos estudantes está relacionada com a possibilidade de contextualizar conceitos na qual estudantes e professores podem se referir ao mesmo objeto "sob o ponto de vista psicológico, o que faz com que os conceitos cotidianos se façam presentes e passem a interagir com os conceitos científicos que são introduzi- 
dos" (MALDANER et al., 2001, p. 6), fazendo com que, por meio da interação, os estudantes se apropriem do conceito científico estudado na escola. Neste sentido, destaca-se um importante aspecto defendido na SE: a permanente significação conceitual.

No desenvolvimento de uma SE, cada professor trabalha os conceitos referentes à sua disciplina, necessários para o entendimento da situação real. Maldaner (2007a, p. 245) afirma que "cada dimensão analisada permite significar um conjunto de conceitos pertencentes a um sistema conceitual, que se traduz em disciplina escolar, o que, ao mesmo tempo, permite transgredir as fronteiras disciplinares.” Neste sentido,

[...] é importante que a palavra, representativa do conceito, esteja presente, seja usada na interação, os atores se detenham nela, discutam sentidos e significados que deverá ter em um contexto específico de uma disciplina ou no contexto inter e transdisciplinar. Ao evoluir o significado, o conceito passará a constituir a mente do aluno, permitindo pensar conceitualmente sobre a situação estudada ou sobre outras situações em que esse conceito se faça necessário. (MALDANER, 2007b, p. 10-11)

Em outros termos, o conceito pode ganhar novos significados à medida que é articulado a outras situações ou a outros contextos de discussão, nas interações, em diferentes disciplinas escolares e SE.

$\mathrm{Na}$ sequência, apresentam-se os pressupostos epistemológicos, em especial quanto à visão de Ciência e produção de conhecimento, que foram identificados com base na análise dos textos publicados no âmbito do Gipec e da entrevista semiestruturada com um dos professores do grupo.

\section{Pressupostos epistemológicos que balizam a SE}

Segundo os propositores da SE, no seu desenvolvimento, é importante a presença das questões epistemológicas que se referem "à produção da ciência e à sua validação" (MALDANER et al., 2007, p. 130); afinal,

[...] a Ciência não se apóia nas aparências e nem busca essências escondidas na natureza. É, a Ciência, uma construção humana, portanto, histórica, que se dá com o desenvolvimento de conceitos ou idéias que se confrontam com os dados sensoriais e as convicções espontâneas. (MALDANER et al., 2007, p. 130)

Embora seja "difícil definir o que seja Ciência, ou colocar sob uma única definição tudo o que se faz com o nome de Ciência" (MALDANER, 2003, p. 100), neste texto, apresentam-se algumas definições que constituem os pressupostos epistemológicos identificados na análise dos textos publicados referentes a SE e que foram defendidos pelo professor entrevistado (PE). Com base em Lemke (1997), entende-se que "a Ciência é uma forma de falar sobre experiências familiares e não familiares” (ZANON; MALDANER, 2010, p. 125). Na SE, a Ciência também 
[...] é significada como uma criação cultural/histórica específica, como um conhecimento estruturado que, simplificando a complexidade do real, tem grande potencialidade de ser inserida como uma compreensão relevante sobre "algo" no mundo, co-participando no cumprimento da função fundamental e insubstituível da escola, na apropriação de linguagens e pensamentos específicos capazes de uma nova ação no meio. (MALDANER et al., 2007, p. 116)

O conhecimento químico, segundo Maldaner et al. (2007), só foi possível com a utilização de ferramentas culturais próprias, como linguagens, pensamentos, conceitos, teorias e modelos compreensivos do real e que mantêm amplas relações com conhecimentos produzidos em outras Ciências. Conhecimento esse "culturalmente produzido e validado no seio de uma comunidade argumentativa própria [que] requer instrumentos culturais constitutivos do seu modo peculiar de estruturação, ação e referenciação" (MALDANER et al., 2007, p. 116-117).

No contexto da SE, entende-se que o conhecimento e o entendimento acerca do que é produzido pelo homem são construídos "quando indivíduos se engajam socialmente em conversações e atividades sobre problemas e tarefas comuns" (DRIVER et al., 1999, p. 34 apud MALDANER et al., 2007, p. 117). Segundo o professor entrevistado (PE), essa compreensão está em sintonia com a base vigotskiana, no sentido de que o conhecimento "não é construído espontaneamente", mas em processos intersubjetivos relacionados ao enfrentamento de problemas comuns, o que remete para a necessidade de o professor introduzir conhecimentos específicos.

Também é defendida a compreensão do conhecimento científico não como solucionador de todos os problemas da humanidade (MALDANER; ZANON; AUTH, 2007), mas, sim, como um conhecimento que pode gerar benefícios ou malefícios a ela (ARAÚJO; AUTH; MALDANER, 2007).

Não é aceita a idéia de Ciência cristalizada, imutável e produtora de verdades às quais não cabem questionamentos. [...], pois quem produz Ciência dificilmente admite verdades definitivas. Ao contrário, coloca em dúvida o estabelecido pelas produções já feitas. (AUTH et al., 2004, p. 255)

O professor entrevistado (PE) explica que a SE "surge de um trabalho de equipes que há muitos anos vem discutindo a necessidade de pensar o conhecimento científico na sua compreensão mais genuína, que é um sistema conceitual". Neste sentido, acrescenta que: "O conhecimento científico é sempre um sistema conceitual e, portanto, ele tem ordenamentos, ele é absolutamente descontextualizado, ou seja, ele é um sistema em que há níveis de generalidade diferentes, em que os conceitos se entrelaçam, se relacionam" (PE).

Em cada campo do saber, que tem um sistema conceitual que o caracteriza, "os conceitos constituem a consciência das pessoas e permitem a formação de um pensamento e de uma ação, ou seja, passam a existir como conhecimento historicamente recriado" (MALDANER; ZANON, 2004, p. 54-55). A fala de PE remete para a especificidade do conhecimento científico, diferenciando-o do conhecimento escolar ou cotidiano. 
Nos pressupostos epistemológicos inspiradores da SE, identificados na análise dos textos, é preciso incluir algumas das discussões de Bachelard, segundo PE. De acordo com o epistemólogo, o conhecimento científico é construído a partir do rompimento com o conhecimento comum. Nas palavras de Lopes (1996, p. 261): "Na medida em que o real científico se diferencia do real dado, o conhecimento comum, fundamentado no real dado, no empirismo das primeiras impressões, é contraditório com o conhecimento científico". Neste sentido, PE ressalta que a discussão de Bachelard sobre o real dado e o real produzido está aliada às ideias de Vigotski (2001) sobre as inter-relações necessárias ao ensino e aprendizagem de Ciências.

\begin{abstract}
"O real dado, ele precisa ser compreendido em cada momento histórico pelo real produzido já existente. Quer dizer, esse real produzido permite você estudar o real dado. Ou seja, você tem que romper com o real dado para poder visitar o real produzido. Agora, como se faz isso? Aí, tem o Vigotski para nos ajudar [...], porque o real produzido ele precisa ter uma âncora, $[. .$.$] as vivências dos alunos, que com base$ nas palavras, vão sendo encharcadas de sentidos conforme a ciência. Então, tu tens esse movimento duplo: ascendente e descendente. Você tem o desencadeamento dos movimentos, [...], eles são descendentes, mas é sobre algo. Agora, à medida que ele começa a ter sentido, aí você passa a ter a possibilidade de compreender esse real dado de forma menos ingênua, [...] de explicações, além das aparências. E a ciência é, necessariamente, além das aparências". (PE)
\end{abstract}

Assim, a compreensão da realidade dada torna-se possível por meio da significação dos conceitos científicos. Contudo, destaca-se que não há a compreensão, no contexto da SE, de que "o pensamento científico ou pensamento abstrato e descontextualizado seja superior a outras formas (sempre mediadas) de pensar e agir", mas que proporcionam "o contato com instrumentos culturais próprios de uma sociedade científica, que é histórica, é real” (MALDANER, 2003, p. 107).

Esses fundamentos epistemológicos balizam a organização curricular baseada em sucessivas SE, o que torna relevante a discussão, apresentada na sequência, de como tais fundamentos implicam ou vêm sendo trabalhados no âmbito educacional em que se propõe SE.

\title{
Implicações de pressupostos epistemológicos no ensino e na formação docente
}

Como já discutido anteriormente, os propositores da SE destacam a importância das questões epistemológicas em seu desenvolvimento e enfatizam que ela está balizada principalmente pelas ideias de Bachelard e Vigotski.

Com base em Vigotski (2000, 2001), defende-se que é na escola que são formadas, de forma intencional, capacidades mentais específicas que permitem às pessoas tomarem decisões com maior discernimento diante de situações $\operatorname{concretas}^{6}$ da vida (ARAÚJO; AUTH; MALDANER, 2005). Na SE, se questiona a verdade absoluta, única e irrefutável, defendendo-se os processos intersubjetivos e intercomunicativos, compreendidos como fundamentais 
na constituição do ser humano (ARAÚJO; AUTH; MALDANER, 2007). Quanto à compreensão de que na SE não é aceita a ideia de ciência cristalizada, colocando-se em dúvida as produções já feitas, o PE afirma que

"A SE é, no plano ontológico, [...] uma caminhada histórica, [...], com variação de sentidos e significados que vão ter que ir se produzindo, sempre tem que recorrer, [...] isso também está baseado em Vigotski com aquela [compreensão] de que os conceitos evoluem, os sentidos evoluem, os significados evoluem. Então, na SE, por isso tem que ter uma finalização, porque a finalização, ela retoma, e entre SE sucessivas também há essa recorrência. Quer dizer, você volta a testar os sentidos que você produziu, então nesse aspecto, você sempre coloca em dúvida o que você tinha entendido antes, você confronta novamente, se aquele sentido que você produziu está sendo adequado naquele caso". (PE)

Neste sentido, a caminhada histórica possibilita sucessivas ressignificações e retificações conceituais. Os conceitos ensinados não são entendidos como apreendidos, pelos estudantes, na primeira intervenção do professor, pois há movimentos de "recorrência" aos conceitos já estudados, desenvolvendo um sistema conceitual que permita aos alunos fazerem generalizações e abstrações (VIGOTSKI, 2001) coerentes com as Ciências.

Ao conceber "o conhecimento como elaboração histórica que se estabiliza no tempo e que é constantemente recriado nas interações sociais" (MALDANER; ZANON, 2004, p. 54-55), PE ressalta que, no desenvolvimento da SE, o significado (que pode ser entendido como o sentido estabilizado) se "estabiliza em diversos momentos" no processo de ensino. $\mathrm{Na}$ finalização da SE, "o aluno precisa produzir algo, que é para além das provas. [...], obviamente as provas são importantes, mas são sempre as provas sobre situações reais novas e que ele vai ter que usar conceitos que ele significou de alguma forma para poder fazer a sua explicação" (PE). Além disso, o trabalho a partir de SE busca problematizar visões simplistas de Ciência e do seu ensino, considerando que o processo de elaboração do conhecimento escolar é dinâmico e estabelece a mediação entre saberes científicos e saberes cotidianos (MALDANER et al., 2007).

Em relação à contextualização histórica da produção do conhecimento científico, PE argumenta que não considera viável, em função da limitação dos tempos da escola básica, contextualizar todo o processo histórico de determinado conhecimento, pois, normalmente, se consegue apresentar apenas "uma caricatura". Neste sentido, defende que, em alguns casos, deve-se usar a autoridade pedagógica para inserir, de forma mais objetiva, aspectos históricos do conhecimento produzido.

${ }^{6}$ Segundo Maldaner (2007a, p. 245), concretas são "as situações de vivência dos alunos, os fenômenos naturais e artificiais e as aplicações tecnológicas". 
"É uma autoridade. Então eu vou usar essa autoridade pedagógica, sim. Eu não preciso começar sempre do começo [...], eu prefiro dizer assim: bom, usar a característica recorrente da história, [...]”. (PE)

Desta forma, o professor deve assumir a introdução de uma Ciência social e historicamente construída. Nas palavras de PE: “[...] eu tenho consciência absoluta de que estou trazendo uma ciência pronta, só que essa ciência pronta ${ }^{7}$, para o aluno, vai começar a se constituir, eu estou trazendo, mas ela não está pronta pra ele [o aluno]." Segundo PE, nesse contexto, podem ser inseridos os modelos explicativos, presentes no ensino de Ciências e que são aceitos, a exemplo de como se organizam as partículas em um átomo ou molécula. PE afirma:

"É lógico que você vai falar que são modelos. Mas para ele no começo são realidades, o oxigênio é real, eu preciso dele, [...], no começo ele é bastante real, mas depois, nós compreendemos substância pelas suas características, pela massa que tem, como dois átomos ligados, então você já vai para o modelo de ligação química [...]”.

Em suma, na SE, considera-se importante contemplar alguns aspectos históricos no ensino de Ciências, assim como o ensino da especificidade do conhecimento científico. Entretanto, apontam-se limites da possibilidade de compreensão dessas características da Ciência, no âmbito do Ensino Médio.

Ainda quanto a aspectos mais gerais, relacionados a implicações da concepção epistemológica de integrantes do Gipec, entende-se que

[...] a situação de estudo se abre para outras relações, mais gerais e globais, por meio das Ciências, num ir e vir dialético que permite construir formas mais dinâmicas de saber - de significação e de uso de saberes - no contexto em que concorrem formas científicas diversas de explicação, com as linguagens e modelos explicativos que lhes são peculiares. [...] As situações da vivência permitem que [...] conceitos do cotidiano se façam presentes e passem a interagir com conceitos científicos introduzidos, permitindo que ambos se inter-relacionem e se configurem em novos níveis [...]. (MALDANER; ZANON, 2004, p. 60)

Na SE, a significação dos conceitos se dá pela interação e interlocução entre os sujeitos participantes do processo de ensino e aprendizagem. Nesse contexto, destaca-se o papel do professor (ou outro sujeito) como alguém que sabe mais sobre os significados históricos,

\footnotetext{
${ }^{7} \mathrm{O}$ termo 'ciência pronta' decorre de um sentido histórico, ou seja, ensina-se na escola sobre um conhecimento já estabilizado social e historicamente, ainda que a ciência ou o conhecimento científico esteja em permanente recorrência ou reelaboração, como é evidente em excertos da análise dos artigos analisados sobre SE e na fala de PE que será expressa mais adiante.
} 
científicos e culturais, e que tem, portanto, a função de mediar o aluno no processo de compreensão dos conceitos científicos. Esse processo pode começar com a fala, ou seja, com a introdução das palavras específicas da Ciência que expressam significados sobre a situação real em estudo para, com isso, possibilitar, de acordo com o professor entrevistado (PE): "os movimentos ascendentes e descendentes entre um sujeito que está começando a aprender a vivência dele num novo nível e ao mesmo tempo consegue dar significado para as palavras novas introduzidas, que são dos conceitos científicos".

Com base em Bachelard (1983), compreende-se que o trabalho pedagógico desenvolvido a partir de SE busca enfocar dois mundos: o da realidade dada que chega até nós pelos sentidos, pelo concreto e percepções relacionadas do contato direto com objetos; e o da realidade produzida, que se relaciona com o sistema conceitual específico, a objetos teóricos ou entidades teóricas, como os átomos, moléculas, elétrons que permeiam o conhecimento científico e são os objetos reais da Ciência.

Segundo Vigotski (2001, 2005), no processo de formação conceitual, o conceito espontâneo (ou cotidiano) e o conceito científico (ou não espontâneo) são construídos em "movimento duplo: ascendente e descendente" (PE). O conceito espontâneo tem como ponto de partida a experiência concreta e caminha para a abstração, enquanto o conceito científico parte do abstrato para o concreto. Isso decorre das diferentes formas pelas quais os dois tipos de conceitos surgem; enquanto o conceito espontâneo tem origem no confronto com uma situação concreta,

[...] um conceito científico envolve, desde o início, uma atitude "mediada" em relação a seu objeto. Embora os conceitos científicos e espontâneos se desenvolvam em direções opostas, os dois processos estão intimamente relacionados. [...] os conceitos científicos desenvolvem-se para baixo por meio dos conceitos espontâneos; os conceitos espontâneos desenvolvem-se para cima por meio dos conceitos científicos. (VIGOSTKI, 2005, p. 135-136)

$\mathrm{Na}$ SE, com base em Bachelard (1996), entende-se a ruptura com o senso comum como necessária para a instauração do espírito científico e a produção do conhecimento científico. No entanto, com a ruptura, "se vão saberes que permitiam viver, escolher alternativas e plantar esperanças" (ARAÚJO; AUTH; MALDANER, 2007, p. 246). Neste sentido, avançase, com base em Santos (1989, p. 246-247), para "a idéia de uma segunda ruptura, que permita o retorno do conhecimento científico produzido ao senso comum, cuja interação deixe-o com mais sentido, mais sistemático e menos comum”.

Essa percepção é coerente com a percepção de movimentos ascendentes e descendentes de Vigotski (2005): ambas as compreensões remetem para que a evolução conceitual aconteça. Tal evolução está relacionada aos novos significados que os conceitos, tanto os científicos quanto os cotidianos, podem adquirir a partir de novas relações estabelecidas. Não há a substituição do conceito espontâneo pelo conceito científico, nem vice-versa, mas um sistema de conceitos que convivem, entram em conflito e alimentam-se mutuamente. Ou seja, na SE, o trabalho pedagógico teria a proposição de favorecer tanto o movimento dos conceitos espontâneos em direção à abstração, quanto o movimento dos conceitos científicos no 
sentido da concretude, da realidade percebida. Portanto, a significação conceitual está relacionada à apropriação dos conceitos científicos pelo aluno, que é favorecida, no âmbito da SE, pela abordagem contextualizada e interdisciplinar dos conceitos, via estudo de uma situação vivencial em que os conceitos cotidianos dos estudantes são considerados e (re)significados, em que conhecimentos e práticas, à luz das ciências, possibilitam novas compreensões e ações sobre a realidade vivenciada.

Também se ressaltou, na entrevista, o fato de a situação real em estudo, na concepção do professor entrevistado (PE), ser

"[...] sempre complexa, ela sempre precisa muitos ângulos de análise. E aí a gente entra então com a necessidade da abordagem transdisciplinar, a situação de estudo é por natureza transdisciplinar [...] ela precisa das disciplinas para além das mesmas, então, você tem que ter também intercâmbio entre os sistemas conceituais".

A característica transdisciplinar remeteu para a necessidade de se introduzir mais um referencial à SE: Edgar Morin. Segundo o professor entrevistado, este autor dá aporte teórico para a abordagem de questões transdisciplinares e para a compreensão ampla das mesmas, num nível que o grupo de pesquisa considera mais adequado para o enfrentamento de problemas, ou seja, o enfrentamento de situações reais, que são complexas.

Com aporte em Morin (2000, 2006), busca-se ampliar a compreensão acerca da complexidade das práticas, das teorias e, também, das relações entre teorias e práticas (ZANON; MALDANER, 2010). Considera-se a complexidade e a pluralidade da realidade e dos fatos, em suas múltiplas facetas de olhar e compreensão, focando o estudo de "objetos complexos" (ZANON; MALDANER, 2010, p. 120, grifo dos autores) que permitem novas percepções sobre situações-problema, a exemplo de questões socioambientais, a partir das ciências, construindo conhecimento escolar. A complexidade, em Morin (2006, p. 38), refere-se ao "que foi tecido junto", de modo que "há um tecido interdependente, interativo e inter-retroativo entre o objeto de conhecimento e seu contexto, as partes e o todo, o todo e as partes, as partes entre si. Por isso a complexidade é a união entre a unidade e a multiplicidade" (MORIN, 2006, p. 38).

A SE implica a ressignificação de concepções teóricas e práticas, por isso, envolve saber lidar com inseguranças, desafios e incertezas. Entretanto, a superação dessas dificuldades ocorre a partir do trabalho coletivo, na construção de espaços para estudo e planejamento em grupo (ZANON; MALDANER, 2010). A conquista de tempo e espaço para a reorganização curricular constitui um desafio a ser enfrentado na elaboração e desenvolvimento de propostas da natureza da SE.

$\mathrm{Na}$ entrevista e em textos publicados, chama-se atenção à importância de que, na formação docente, se desenvolva "a reflexão epistemológica sobre a produção de uma ciência e a sua validação" (MALDANER et al., 2007, p. 130), ou melhor, sobre a natureza do conhecimento científico e sua constituição como bem cultural da humanidade (MALDANER, 2000). Afinal, a carência de tais discussões influencia "a compreensão do currículo desenvolvido nas escolas e as possibilidades de inovação, limitando a aprendizagem e o conseqüente desenvolvimento cultural dos estudantes em novos níveis" (ARAÚJO; AUTH; MALDANER, 2007, p. 246). 
Assim, considerando a necessidade de discussões de cunho epistemológico na formação docente, o Gipec da Unijuí busca trabalhar os pressupostos epistemológicos da SE na formação inicial e continuada de professores. A ênfase para a necessidade de se trabalharem esses aspectos na formação de professores se justifica, pois na SE

[...] o estudo tem em vista os conhecimentos, e disso decorre a necessidade da explicitação epistemológica dos processos de significação atingida, bem como da explicitação das visões de ciência, mundo, currículo, aprendizagem, papel de aprendiz e professor e outros. (MALDANER; ZANON; AUTH, 2007, p. 65)

No âmbito da formação inicial, a discussão em torno da organização curricular via SE e seus pressupostos epistemológicos ocorre, sobretudo, por meio de disciplinas dos cursos de Licenciatura em Química e em Biologia (FRISON et al., 2009). No contexto das escolas, as discussões acontecem nos momentos de formação, organizados e coordenados pelo Gipec. Desses encontros participam os professores pesquisadores, estudantes da graduação e pósgraduação e professores da Educação Básica, ou seja, o processo formativo se dá por meio da interação entre Universidade-Escola e inclui sujeitos da formação inicial e continuada. As atividades formativas configuram um importante espaço de estudo coletivo e ressignificação da prática educativa. O PE chama a atenção para a necessidade de formação docente permanente para a efetivação do trabalho a partir de SE na escola, pois é necessário um esforço para que os professores consigam compreender, de forma mais ampla, os aspectos epistemológicos, de modo que os mesmos realmente estejam presentes no seu fazer pedagógico.

O PE também afirma que os estudantes de graduação sentem dificuldades em romper com a estrutura linear com que os conteúdos são tratados tradicionalmente. O professor percebe essas dificuldades nas atividades em que os estudantes precisam produzir propostas de ensino a partir de SE, por meio das quais terão de contemplar um núcleo de conceitos e organizar o estágio docência, na escola. Em função disso, defende-se a continuidade do trabalho, que já começa nos cursos de licenciatura. PE argumenta que os estudantes nem sempre

“[...] conseguem o primeiro nível de reorganização de conteúdos, ao menos nos primeiros anos. Aí então a necessidade de continuidade e de grupos de estudo e debates é crucial. Ou seja, se nós não nos convencermos que isto é um esforço permanente na vida dos professores, a gente não pode ter muita expectativa" (PE).

Entretanto, apesar das dificuldades expressas por PE quanto à constituição de fundamentos epistemológicos mais consolidados junto à formação inicial de professores, o mesmo expressa grandes avanços quando tais questões são trabalhadas na formação continuada, como os acompanhados em escolas parceiras do Gipec da Unijuí.

Segundo o PE, "quando tu acompanha um grupo de professores na escola e aí você tem a presença dos estagiários e estudantes, e a gente mesmo [referindo-se a ele e outros pesquisadores], daí a gente consegue ir longe". Como exemplo, PE cita a SE sobre o 'Câncer', em que as atividades realizadas por meio da integração Universidade-Escola possibilitaram a 
organização do programa escolar envolvendo "[...] disciplinas da área das Ciências da Natureza e suas Tecnologias, além de Português, Geografia e outras matérias, e [...] foi efetivamente trabalhado com muita intensidade por duas professoras do Gipec durante, acho que dois anos [...]" (PE). Com a colaboração e o acompanhamento das pesquisadoras, os professores se envolveram nas atividades propostas e assumiram a produção de materiais para o desenvolvimento da referida SE (BOFF, 2011). Ou seja, trata-se de um processo lento em que a parceria Universidade-Escola pode possibilitar um trabalho contínuo de formação continuada que dá autonomia para os professores produzirem e desenvolverem novas SE. Neste sentido, a SE "não pode ser uma produção pronta, feita por alguém que vai aplicar. Ela precisa ser assumida num coletivo que pode ser os professores de uma disciplina do ensino médio ou ensino fundamental, mas de preferência entre mais de uma disciplina, ou por uma área" (PE).

O entrevistado ressalta diferenças no trabalho a ser desenvolvido junto aos estudantes da graduação e do Ensino Médio. Ele defende que

\footnotetext{
"na graduação a historicidade do conhecimento deve ser uma preocupação constante dos professores, diferente do ensino médio. No ensino médio é a própria natureza do tipo de ensino que se faz, que permite mostrar ao aluno que a ciência é um bem cultural é que está em construção, que é histórica. [...] eu sinto que os alunos têm uma vontade de ouvir isto. De saber que dava pra pensar diferente, [...]. Então eu posso, dentro de um sistema conceitual, que mantém uma certa lógica, mesmo que se mostre errado, sob o ponto de vista de conhecimento de hoje, eu posso pensar o mundo, sem problema nenhum, isto me permite, por exemplo, pensar o mundo, como feito de bolinhas de átomos, átomos como bolinhas, perfeitamente". (PE)
}

Segundo PE, na SE, a função do conhecimento historicamente produzido é auxiliar o estudante a "saber pensar o mundo do ponto de vista da cultura que lhe cobra, a cultura hoje, o contexto cultural cobra dele conhecimento para ele poder se virar. E ele sabe que na escola terá a oportunidade de compreender isso, e que é diferente daquilo que ele vive [no contexto cotidiano]."

Desta forma, compreende-se, a partir dos pressupostos epistemológicos identificados e das implicações dos mesmos, que a proposta de ensino analisada neste estudo contempla alguns princípios da visão epistemológica e educacional construtivista. No campo epistemológico, o construtivsmo supera a concepção empirista e apriorista/inatista do processo de construção do conhecimento científico (GALIAZZI, 2008; MORAES, 2008). Ao se considerarem aspectos da epistemologia de Bachelard, alguns pressupostos defendidos na SE convergem com o construtivismo epistemológico.

No campo educacional, uma das vertentes construtivistas está balizada nos pressupostos de Vigotski, conforme discussão realizada por Moraes (2008). O autor apresenta alguns princípios defendidos por Vigotski, sendo possível sinalizar que os mesmos se fazem presentes na SE: 
1) Todos estamos imersos num discurso cultural a partir do qual construímos nossos conhecimentos; 2) A escola ser fundamental na construção dos conceitos científicos; 3) Os conceitos podem ser tanto construídos de forma indutiva (concepções espontâneas, do senso comum) quanto de forma dedutiva (concepções científicas); 4) A mediação do adulto e, especialmente, do professor, é essencial na aquisição de novos conceitos dentro da zona de desenvolvimento potencial dos alunos; e 5) O desenvolvimento de novos conceitos provoca transformações no significado dos conceitos já existentes, dando lugar a uma contínua reestruturação cognitiva do aluno. (MORAES, 2008, p. 113-114)

Contudo, Galiazzi (2008, p. 151) defende "que para aplicar os princípios construtivistas e não cair no relativismo de que qualquer ação pode ser aceitável, é preciso, em grupo, trabalhar e pesquisar a própria prática pedagógica". Neste sentido, os aspectos levantados neste trabalho, sobre a formação docente, estão em sintonia com a posição da autora supracitada, pois destaca-se a dimensão coletiva assumida pelo Gipec no processo de formação de professores, assim como o incentivo para que os docentes participem e se envolvam nas investigações realizadas pelo grupo.

\section{Algumas considerações}

Em suma, a SE contempla aspectos da visão construtivista, tanto na dimensão epistemológica quanto na dimensão educacional. Busca-se, com a referida proposta, contemplar um ensino contextualizado, inter e transdisciplinar, que corrobore com aspectos defendidos nas orientações curriculares nacionais. Foca-se em uma 'situação concreta', complexa, que professores e estudantes buscam compreender de forma ampla. Para que ocorra essa compreensão, a abordagem do objeto de estudo inclui diversos níveis de abstração e a exploração de diversas fontes de informações.

Em função da organização proposta, os conceitos (ou conhecimentos) cotidianos são significados, a partir do contexto vivencial dos estudantes, e têm oportunidade de evoluir, ou seja, a eles podem ser atribuídos novos significados à medida que são introduzidos para o entendimento de novas situações. Ressalta-se ainda que o professor é responsável por mediar o processo de ensino e de aprendizagem, de forma a transacionar significados necessários e em nível de entendimento compatível com os estudantes.

Para contemplar tais perspectivas, pode-se inferir, com base na análise dos textos publicados no âmbito do Gipec e da entrevista desenvolvida com um dos professores do grupo, que os principais referenciais centram-se em Bachelard e Vigotski como aliados na defesa da SE. No campo pedagógico, o principal aporte teórico da SE está centrado nas ideias de Vigotski (2000, 2001, 2005), especialmente as discussões em torno da significação conceitual e nas interações sociais. No campo epistemológico, busca-se referência na concepção de real dado e real produzido e na recorrência histórica defendida por Bachelard (1983). 
Ainda que a gênese da SE seja ancorada em Vigotski (2000, 2001, 2005) e Bachelard (1983, 1996), também é pertinente a compreensão de que a proposta não se finda, mas está em permanente reconstrução, tal como sugere a perspectiva teórica adotada na SE. Deste modo, a SE está, a todo momento, sendo avaliada, criticada, analisada e repensada para o contexto da escola básica e o contexto da formação docente, incorporando, transformando e reafirmando conhecimentos, tendo em vista os problemas ou mudanças de concepção de ensino que constituem o cenário histórico dos distintos professores e pesquisadores que trabalham com tal perspectiva em distintos contextos escolares.

Entre os pressupostos epistemológicos defendidos pelo grupo, pode-se destacar a compreensão de que a Ciência é uma construção humana, histórica, com linguagem específica, e que se dá com o desenvolvimento de um sistema conceitual produzido e validado nas interações sociais, em especial, no contexto da comunidade científica. Tais conhecimentos que se encontram em permanente processo de (re)construção, confrontam-se com os dados sensoriais e as convicções espontâneas, o que remete para uma eterna vigilância ao conhecimento produzido e que possibilita compreensões sobre a realidade dada.

Entretanto, assumir tais compreensões implica repensar o currículo e o desenvolvimento do mesmo em sala de aula. A SE, inspirada em Vigotski (2001), defende que o conhecimento escolar seja produzido a partir do conhecimento cotidiano do estudante, para que, nas interações assimetricamente desenvolvidas sobre o objeto em estudo, possa apropriar-se do conhecimento historicamente produzido. Considerando isso, defende-se, neste estudo, a importância da vigilância epistemológica, por parte do professor, ao modo como se apresentam as discussões nas aulas, de maneira que: os problemas (gênese do conhecimento) sejam apresentados aos estudantes; que o contexto vivencial em estudo seja articulado à inclusão de novas linguagens e pensamentos, característicos às Ciências da Natureza, como as palavras átomo, substância, mistura, energia, que não são aprendidas pela mera definição conceitual ou elaboração de listas de exercícios repetitivos, mas por processos de apropriação permanente de sentidos e significados aos conceitos, nas interações (VIGOTSKI, 2001), via movimentos ascendentes e descendentes, entre conceitos cotidianos e científicos (VIGOTSKI, 2005).

Quanto à coerência entre a perspectiva epistemológica defendida pelo Gipec sobre SE e suas implicações no cenário educacional, apontam-se limites na compreensão mais adequada sobre a natureza da Ciência, a exemplo da formação inicial de professores, em que os licenciandos têm dificuldades em superar perspectivas tradicionais de ensino, não conseguindo, muitas vezes, ter uma visão ampla de Ciência e de conhecimento científico. No entanto, também se percebem avanços significativos quando é desenvolvido o trabalho no âmbito da formação continuada de professores e no processo de ensino desenvolvido por sucessivas SE.

Neste sentido, defende-se que discussões de cunho epistemológico sejam contempladas no processo de formação inicial e continuada dos professores. Para isso, um dos aspectos a ser destacado, no contexto da SE, é a integração Universidade-Escola, como um importante espaço para se repensar o processo de formação docente, contemplando sistematicamente a dimensão epistemológica necessária ao fazer educativo, para além dos aspectos organizacionais e metodológicos. Pressupostos epistemológicos e educacionais da SE são desenvolvidos junto aos licenciandos e professores da Educação Básica por meio dos momentos formativos organizados e coordenados pelo Gipec, nos quais se prioriza a dimensão coletiva do fazer educacional. 
Pressupostos epistemológicos que balizam ...

A análise de pressupostos epistemológicos que fundamenta uma das abordagens temáticas analisadas neste artigo, a SE, pode contribuir com a área de Educação e Ensino de Ciências, pois possibilita a orientação de práticas de ensino mais coerentes com perspectivas que vêm sendo defendidas na área. Entende-se que também seria importante a identificação de pressupostos epistemológicos que orientam demais tipos de abordagem por temas, como a abordagem temática freiriana e dos currículos com ênfase CTS, que possibilitariam caracterizar convergências e divergências frente a propostas defendidas por distintos grupos de pesquisa, possibilitando a sinalização de avanços e desafios necessários.

Resultados apresentados visam possibilitar maior discernimento quanto aos fundamentos que balizam uma proposta de ensino, como a que remete para a reconfiguração curricular que é desenvolvida por sucessivas SE. Também ajudam a repensar sobre o desenvolvimento de processos de ensino e formação docente, de modo a aprender Ciências e sobre Ciências (visão de Ciências e produção de conhecimento), evitando-se visões vinculadas ao processo de produção do conhecimento científico que sejam, por exemplo: empírico-indutivista e ateórica, rígida/acabada, a-problemática, a-histórica, exclusivamente analítica, individualista, descontextualizada e socialmente neutra (GIL PÉREZ et al., 2001).

\section{Referências}

ARAÚJO, M. C. P.; AUTH, M. A.; MALDANER, O. A. Autoria compartilhada na elaboração de um currículo inovador em ciências no ensino médio. Contexto e Educação, Ijuí, v. 22, n. 77, p. 241-262, 2007.

. Identificação das características de inovação curricular em ciências naturais e suas tecnologias através de situações de estudo. In: ENCONTRO NACIONAL DE PESQUISA EM EDUCAÇÃO EM CIÊNCIAS, 5., 2005, Bauru. Atas... São Paulo: ABRAPEC, 2005. p. $1-12$.

. Situações de estudo como forma de inovação curricular em ciências naturais. In: GALIAZZI, M. do C. et al. (Org.). Construção curricular em rede na educação em ciências: uma aposta de pesquisa na sala de aula. Ijuí: Editora Unijuí, 2007. p. 161-176.

AULER, D.; DALMOLIN, A. M. T.; FENALTI, V. dos S. Abordagem temática: natureza dos temas em Freire e no enfoque CTS. Alexandria: revista de educação em ciência e tecnologia, Florianópolis, v. 2, n. 1, p. 67-84, 2009.

AUTH, M. A. Formação de professores de ciências naturais na perspectiva temática e unificadora. 2002. 200 f. Tese (Doutorado em Educação) - Centro de Ciências da Educação, Universidade Federal de Santa Catarina, Florianópolis, 2002.

AUTH, M. A.; MELLER, C. B. (Org.). Situação de estudo: ser humano e ambiente: percepção e interação. Ijuí: Editora Unijuí, 2005.

AUTH, M. A. et al. Situação de estudo na área de ciências do ensino médio: rompendo fronteiras disciplinares. In: MORAES, R.; MANCUSO, R. (Org.). Educação em ciências: produção de currículos e formação de professores. Ijuí: Editora Unijuí, 2004. p. 253-276. 
Sangiogo, F. A. et al.

BACHELARD, G. Epistemologia: trechos escolhidos por Dominique Lecourt. 2. ed. Rio de Janeiro: Zahar, 1983.

A formação do espírito científico: contribuição para uma psicanálise do conhecimento. Rio de Janeiro: Contraponto, 1996.

BOFF, E. T. O. Processo interativo: uma possibilidade de produção de um currículo integrado e constituição de um docente pesquisador-autor e ator de seu fazer cotidiano escolar. 2011. 318 f. Tese (Doutorado em Educação em Ciências) - Instituto de Ciências Básicas da Saúde, Universidade Federal do Rio Grande do Sul, Porto Alegre, 2011.

BOFF, E. T. O.; HAMES, C.; FRISON, M. D. (Org.). Situação de estudo: alimentos, produção e consumo - alimentação humana. Ijuí: Editora Unijuí, 2006.

BRASIL. Ministério da Educação. PCN+: orientações educacionais complementares aos parâmetros curriculares nacionais - ciências da natureza, matemática e suas tecnologias. Brasília: SEMT, 2002.

Ministério da Educação. Secretaria de Educação Fundamental. Parâmetros curriculares nacionais: ciências naturais. Brasília, 1998.

CRUZ, S. M.; ZYLBERSZTAJN, A. O enfoque ciência, tecnologia e sociedade e a aprendizagem centrada em eventos. In: PIETROCOLA, M. (Org.). Ensino de física: conteúdo, metodologia e epistemologia numa concepção integradora. Florianópolis: UFSC, 2001. p. 171-196.

DELIZOICOV, D. La educación en ciencias y la perspectiva de Paulo Freire. Alexandria: revista de educação em ciências e tecnologia, Florianópolis, v. 1, n. 2, p. 37-62, 2008.

FORGIARINI, M. S.; AULER, D. A abordagem de temas polêmicos na educação de jovens e adultos: o caso do "florestamento" no Rio Grande do Sul. Revista Electrónica de Enseñanza de las Ciencias, Vigo, v. 8 n. 2, p. 399-421, 2009.

FRISON, M. D. Programa de melhoria e expansão do ensino médio. Ijuí: Editora Unijuí, 2006. 1 CD-ROM.

FRISON, M. D. et al. Ações de estagiárias da licenciatura em química em proposta de inovação curricular. In: ENCONTRO NACIONAL DE EDUCAÇÃO EM CIÊNCIAS, 7., 2009, Florianópolis. Atas... Florianópolis: Editora da UFSC, 2009. p. 1-12.

GALIAZZI, M. C. et al. Construindo caleidoscópicos: organizando unidades de aprendizagem. In: MORAES, R.; MANCUSO, R. (Org.). Educação em ciências: produção de currículos e formação de professores. Ijuí: Editora Unijuí, 2004. p. 65-84.

GALIAZZI, M. C. Algumas faces do construtivismo, algumas críticas. In: MORAES, R. (Org.). Construtivismo e ensino de ciências: reflexões epistemológicas e metodológicas. 3. ed. Porto Alegre: EDIPUCRS, 2008. p. 131-158.

GEHLEN, S. T.; MALDANER, O. A.; DELIZOICOV, D. Momentos pedagógicos e as etapas da situação de estudo: complementaridades e contribuições para a educação em ciências. Ciência \& Educação, Bauru, v. 18, n. 1, p. 1-22, 2012. 
Pressupostos epistemológicos que balizam ...

GIL PÉREZ, D. et al. Para uma imagem não deformada do trabalho científico. Ciência \& Educação, Bauru, v. 7, n. 2, p. 125-153, 2001.

HALMENSCHLAGER, K. R. Abordagem temática: análise da situação de estudo no ensino médio da EFA. 2010. 162 f. Dissertação (Mestrado em Educação Científica e Tecnológica) - Universidade Federal de Santa Catarina, Florianópolis, 2010.

LEMKE, J. L. Aprender hablar ciencia. Barcelona: Paidós, 1997.

LOPES, A. R. C. Bachelard: o filósofo da desilusão. Caderno Catarinense de Ensino de Física, Florianópolis, v. 13, n. 3, p. 248-273, 1996.

LÜDKE, M.; ANDRÉ, M. E. D. A. Pesquisa em educação: abordagens qualitativas. São Paulo: EPU, 1986.

MALDANER, O. A. A formação inicial e continuada de professores de química. 2. ed. Ijuí: Editora Unijuí, 2003.

Concepções epistemológicas no ensino de ciências. In: SCHNETZLER, R. P.;

ARAGÃO, R. M. R de. Ensino de ciências: fundamentos e abordagens. Piracicaba: UNIMEP, 2000. p. 60-81.

Situações de estudo no ensino médio: nova compreensão de educação básica. In: NARDI, R. (Org.). A pesquisa em ensino de ciências no Brasil: alguns recortes. São Paulo: Escrituras, 2007a. p. 239-254.

Ar atmosférico: uma porção do mundo material sobre a qual se deve pensar. In: FRISON, M. D. (Org.). Programa de melhoria e expansão do ensino médio: curso de capacitação de professores da área de ciências da natureza, matemática e suas tecnologias. Ijuí: Editora Unijuí, 2007b. p. 18-46.

MALDANER, O. A.; ZANON, L. B. Situação de estudo: uma organização do ensino que extrapola a formação disciplinar em ciências. In: MORAES, R.; MANCUSO, R. (Org.).

Educação em ciências: produção de currículos e formação de professores. Ijuí: Editora Unijuí, 2004. p. 43-64.

MALDANER, O. A.; ZANON, L. B; AUTH, M. A. A pesquisa sobre educação em ciências e formação de professores. In: SANTOS, F. M. T.; GRECA, I. M (Org.). A pesquisa em ensino de ciências no Brasil e suas metodologias. Ijuí: Editora Unijuí, 2007. p. 49-88.

MALDANER, O. A. et al. Currículo contextualizado na área de ciências da natureza e suas tecnologias: a situação de estudo. In: ZANON, L. B.; MALDANER, O. A (Org.). Fundamentos e propostas de ensino de química para a educação básica no Brasil. Ijuí: Editora Unijuí, 2007. p. 109-138.

MALDANER, O. A. et al. Situação de estudo como possibilidade concreta de ações coletivas interdisciplinares no ensino médio - ar atmosférico. In: ENCONTRO NACIONAL DE PESQUISA EM EDUCAÇÃO EM CIÊNCIAS, 3., 2001, Atibaia. Atas... São Paulo: ABRAPEC, 2001. 
Sangiogo, F. A. et al.

MORAES, R. É possível ser construtivista no ensino de ciências? In: MORAES, R. (Org.). Construtivismo e ensino de ciências: reflexões epistemológicas e metodológicas. 3. ed. Porto Alegre: EDIPUCRS, 2008. p. 103-130.

MORIN, E. A cabeça bem feita: repensar a reforma, reformar o pensamento. Rio de Janeiro: Bertrand Brasil, 2000.

Os sete saberes necessários à educação do futuro. 11. ed. São Paulo: Cortez; Brasília: UNESCO, 2006.

MUENCHEN, C.; AULER, D. Configurações curriculares mediante o enfoque CTS: desafios a serem enfrentados na educação de jovens e adultos. Ciência \& Educação, Bauru, v. 13, n. 3, p. 421-434, 2007.

PINHEIRO, N.; SILVEIRA, R.; BAZZO, W. A. Ciência, tecnologia e sociedade: a relevância do enfoque CTS para o contexto do ensino médio. Ciência $\boldsymbol{\&}$ Educação, Bauru, v. 13, n. 1, p. 71-84, 2007.

SANTOS, B. de S. Introdução a uma ciência pós-moderna. Rio de Janeiro: Graal, 1989.

SANTOS, W. L. P.; MORTIMER, E. F. Uma análise de pressupostos teóricos da abordagem C-T-S (Ciência-Tecnologia-Sociedade) no contexto da educação brasileira. Ensaio: pesquisa em educação em ciências, Belo Horizonte, v. 2, n. 2, p. 133-162, 2000.

UNIVERSIDADE REGIONAL DO NOROESTE DO ESTADO DO RIO GRANDE DO SUL. Grupo Interdepartamental de Pesquisa sobre Educação em Ciências. Geração e gerenciamento dos resíduos sólidos provenientes das atividades humanas. Ijuí: Editora Unijuí, 2002.

VIGOTSKI, L. S. A formação social da mente. São Paulo: Martins Fontes, 2000 2001. A construção do pensamento e da linguagem. São Paulo: Martins Fontes, Pensamento e linguagem. 3. ed. São Paulo: Martins Fontes, 2005.

ZANON, L. B.; MALDANER, O. A. A química escolar na inter-relação com outros campos de saber. In: SANTOS, W. L.; MALDANER, O. A. (Org.). Ensino de química em foco. Ijuí: Editora Unijuí, 2010. p. 101-130.

Artigo recebido em 21/05/12. Aceito em 07/12/12. 